\title{
Köşkdağı Gömü Alanı Mezar Tipleri ve Buluntuları
}

\section{Types of Tombs at Köşkdağı Grave Area and Finds}

\author{
Özge Altun ${ }^{1}$ (1)
}

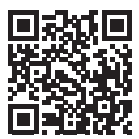

1Sorumlu yazar/Corresponding author: Özge Altun (Dr. Öğr. Üyesi),

Yozgat Bozok Üniversitesi, Fen Edebiyat Fakültesi, Arkeoloji Bölümü, Yozgat, Türkiye

E-posta: ozge.altun@bozok.edu.tr

ORCID ID: 0000-0002-7491-5794

Başvuru/Submitted: 04.09 .2020

Kabul/Accepted: 08.01.2021

Atıf/Citation: Altun, O. (2020). Köşkdağı gömü alanı mezar tipleri ve buluntuları. Anado/u Araştırmaları-Anatolian Research, 23, 193-214. https://doi.org/10.26650/anar.2020.23.790649

\section{öz}

Antik dönemin önemli merkezlerinden bir tanesi olan Kayseri ilinin tarihi MÖ 4. Bin yıllarına kadar gitmektedir. Kent, konumu ve doğal kaynaklarının sağladığı olumlu imkânlar nedeniyle her dönem yerleşim görmüştür. Stratejik konumu Roma İmparatorluk Döneminde başta gelen karargâhlardan bir tanesi olmasını sağlamıştır. Konumu sadece askeri anlamda değil ticari anlamda da önem kazandırmış, geçiş noktalarının merkezinde yer alması sosyal, siyasal, kültürel faaliyetlerin kesintisiz devam etmesini sağlamıştır. Kayseri ilinin zengin tarihsel birikimi maalesef kaçakçıklar için de ilgi çekici bir hale gelmesine neden olmuştur. Bu durum kimi zaman tarihi eserlerin kontrolsüzce açığa çıkmasına ve hasar görmesine neden olmaktadır. Kayseri Müze Müdürlüğü bu gibi durumlarda sistemli kazılar ile müdahalede bulunarak kültürel kalıntıların korunmasına ve belgelenmesine özen göstermektedir. Köşkdağı Gömü Alanı da kaçak kazı inbarı sonucunda açığa çıkarılmış ve çok hasar görmeden Kayseri Müze Müdürlüğü tarafından kazısı tamamlanmıştır. Kazısı tamamlanmış alandaki mezarlar ve buluntular için talebimiz doğrultusunda Kayseri Müze Müdürlüğü tarafından gerekli izinler verilmiştir. Köşkdağı kurtarma kazısında, üç faklı tipte mezar yapısı bulunması ve mezarlarda birden fazla gömü bulunmuş olması nedeniyle kazısı tamamlanan kısım gömü alanı olarak adlandırılmıştır. Mezar tiplerinin çeşitliliği ve mezar buluntuları ile Köşkdağı Gömü Alanı bölgenin ölü gömme gelenekleri ve tarihsel süreçteki yeri hakkındaki bilgilerimize yenilerini eklemektedir. Bu bağlamda literatüre kazandırılması faydalı olacaktır.

Anahtar Kelimeler: Kayseri, Mezar Tipleri, Lahit Mezar, Nekropol

\section{ABSTRACT}

The history of Kayseri, an important center of ancient times, dates to the 4th millennium BC. Due to the positive potentiality provided by the city's location and natural resources, Kayseri has been settled in every period. Strategically located, the city served as one of Imperial Rome's leading headquarters. Kayseri has gained importance not only in the military but also in commercial industry; its location at the center of crossing points has ensured that social, political, and cultural activities continue uninterrupted. Unfortunately, the rich historical accumulation of Kayseri Province has also attracted the interest of smugglers. This situation has sometimes caused historical artifacts to be uncontrollably exposed and damaged. In such cases, the Kayseri Museum Directorate endeavors to protect and document cultural remains by intervening with systematic excavations. The Köşkdağı Burial Site was exposed through illegal excavation. Subsequently, the excavation was completed by the Kayseri Museum Directorate without considerable damage. In accordance 
with our request, the necessary permissions were granted by the Kayseri Museum Directorate for the graves and finds in the excavated area. In the Köşkdağı rescue excavation, the section of completed excavation was determined to be a burial area, since three different types of grave structures were identified, with more than one burial found inside the graves. Thus, the Köşkdağı Burial Site enriches our knowledge about the burial traditions and historical context of this region. These significant findings benefit the existing scope of literature.

Keywords: Kayseri, Grave types, Necropolis, Sarcophagus

\section{EXTENDED ABSTRACT}

\section{Indroduction}

Human beings are emotional by nature. Since long before the great civilizations established mankind, death and separation have eluded full understanding. As a result, civilizations have performed various rituals to honor their deceased. Over time, these rites developed and changed, with different burial customs and grave types emerging. Grave types differ according to the customs and traditions of a society. In addition, the location of the deceased in the society and the community's financial means determine the grave quality. Cemeteries called necropolizes, which were generally created outside of a city, differed between various regions and periods. While cremation burial was preferred in one region, the use of sarcophagi in another period could be preferred. In some cases, more than one type of grave could be found in a single necropolis. Another feature of ancient burial traditions was the repeated use of the same grave. This situation could be valid for family members or for individuals buried in various difficult periods without regard to kin relations.

Accordingly, Anatolian civilizations have exhibited variations in both grave types and burial customs, based on the shifts in societal traditions over time. In addition, various grave types regionally differ. The graves unearthed in the Köşkdağı rescue excavation at Kayseri were likely part of a burial site due to the large number of their burials. The three types of graves in this burial area provide important information about the burial customs of the Kayseri region.

\section{Method}

The Köşkdağı Burial Site was exposed through the rescue excavation carried out by the Kayseri Museum. Five graves were found in the excavation area. Evaluation of these graves revealed their different build types.

Kayseri Museum positively received our request and granted the necessary permissions to document the burial area, evaluate the grave types, and present the findings in literature. After obtaining the work permit of the Burial Site, the initial locations of the tombs were documented through photographs and sketches. Inventory information about the burial area made by Kayseri Museum was provided to us. After completion of the documentation process, 
a literature review was performed to compare each grave type found at the site with similar examples. In addition, the findings of the graves were grouped according to their qualities and their comparison with examples from the literature review. Each find has been evaluated and interpreted in the grave group to which it belongs. Both the structure of the tombs and the finds were compared and found to resemble other examples from ancient times. As a result, a proposal has been submitted for the dates and usage periods of the graves.

\section{Results and Discussion}

In the Köşkdağı district, a burial area was unearthed with a sarcophagus that was discovered through illicit digging and a subsequent rescue excavation. Combined with the presence of different grave structures, the fact that the graves were built in a certain place and order suggests that this area may be a part of the ancient city's necropolis. In the same region, the Garipler Tumulus, which was excavated in 1971, supports this view. However, the partial placement of the ancient city beneath the modern city impedes systematic archaeological excavations. Structural elements and cultural features of the ancient city will be better understood by documenting and evaluating the finds resulting from excavations, such as the Köşkdağı rescue excavation.

We cannot recommend a specific construction year for any of the burial types identified in the burial area. However, we can discern that the sarcophagus was most clearly built during the Roman imperial period. Since the other grave types in the study are the earliest types of graves in Anatolia, their first usage dates are difficult to identify because their use as graves has continued over many years.

Upon evaluation, the gifts of the dead from the graves were dated to the 1 st century AD. Dating can be reliably performed until the middle of the 3rd century AD. In addition, the presence of more than one burial in most of the graves indicates that the graves were used during certain intervals and explains the temporal differences between the gifts of the dead.

The graves unearthed through the rescue excavation show the diversity of the burial traditions in Kayseri throughout ancient times. Moreover, the coins found from the carved tombs indicate that the burial area was in use until the 3rd century AD. Thus, the graves and their finds can be used as correlative sources for the grave types and usage periods that have since been unearthed.

The orderly placement of plates and carved graves, along with the discovery of more than one burial, indicates that the Köşkdağı burial area may have been used as a family cemetery. Although the sarcophagus was found in a singular instance, it contained multiple burials and maintained proximity to the plate tombs, suggesting that this tomb was re-opened for family members. Thus, the Köşkdağ burial area was most likely a cemetery used as a necropolis by families with different financial means. 


\section{Recommendations}

The burial area of Kayseri Köşkdağı gives information about tomb types, tomb finds, and the ancient traditions of Kayseri. Grave types exhibit the burial customs and construction techniques. The finds from the graves constitute important data showing the region's historical background. Particularly, the uncovered coins show the social life in the region and the continuity of the burial area during the Late Roman Period. In this context, this study warrants the attention of regional archaeology. 


\section{Giriş}

Kayseri ili Melikgazi ilçesinde Köşkdağı mahallesinde kaçak kazı bildirimi üzerine Kayseri Müze Müdürlüğü tarafından gerçekleştirilen kurtarma kazısı sonucunda basit çapta bir nekropol alanı açığa çıkarılmıştır. Kazı alanında beş adet mezar açığa çıkarılmıştır. Bu mezarlar değerlendirildiklerinde farklı tiplerde yapıldıkları anlaşılmıştır. Buna göre kazı alanında 1 lahit mezar, 3 plaka tekne mezar ve 2 oygu mezar olmak üzere üç tip mezar yapısı bulunmaktadır.

Kazı alanında lahit mezar ve plaka tekne mezarların aynı doğrultuda yan yana yer aldıkları görülmüştür. Oygu tekne mezarlar ise bu dört mezarın batısına yerleştirilmiştir. Ayrıca oygu tekne mezarların bulunduğu alan düzgün kesme taş bloklarla sınırlandırılmıştır. İki oygu mezar arasına da tekrar kesme taş bloklardan bir sıra örülerek alan ikiye bölünmüştür.

Kaçak kazı sırasında mezarların çok azının tahrip edilmiş olması ve diğer mezarların insitu olarak bulunması yorum yapmamamıza yardımcı olmaktadır. En azından buluntuların yeri ve gömüler karıştırılmamıştır. Mezar içindeki buluntuların ve mezar inşa tekniklerinin farklı oluşu bu alanın tam anlamıyla nekropol olmasa bile özel bir gömü alanı olduğuna işaret etmektedir. Köşkdağı mahallesinde yapılan kazılar sonucunda açığa çıkarılan mezarlar, Roma İmparatorluk Döneminde özgün lahit örnekleri bilinen bölgenin (Koch, 2010, s. 29) ölü gömme gelenekleri ve mezar tipolojisi hakkında yorum yapmamıza olanak sağlamaktadır. Mezarlar içinde birden fazla gömüye rastlanması, mezarların uzun süre tekrar kullanıldıklarına işaret etmektedir. Ayrıca bazı mezarların içinde bulunan ölü hediyeleri mezarların kullanıldıkları dönemlerin bir bölümünü göstermesi açısından önemlidir.

\section{Kazı Alanı ve Mezar Tiplerinin Değerlendirilmesi}

Kurtarma kazısı sonucunda açığa çıkarılmış alan (Çizim 1, Resim 1) mezarlar tipleri ve buluntularıyla birlikte tanımlanıp yorumlanmıştır.

\section{Lahit Mezar}

\section{Bir Numaralı Lahit Mezar}

Ölçüler: uzunluk $255 \mathrm{~cm}$, genişlik $137 \mathrm{~cm}$, yükseklik: $170 \mathrm{~cm}$.

Buluntular: İki cam Unguenterium, Bir bronz bilezik.

Yerel taştan yapılmış olan lahit, kapak kısmı da dâhil olmak üzere detaylandırılmadan bırakılmıştır. Üçgen çatılı olan kapak kısmında köşelere akroter yükseltileri yapılmıştır. Yükseltilerin üçgen formundan palmet şeklinde planlandıkları anlaşılmaktadır. Köşelerinde palmet şeklinde akroterlere sahip üçgen çatılı kapak formu Anadolu üretimi lahitlerde sıklıkla görülmektedir. Bu kapaklar kimi zaman detaylandırılmış olabileceği gibi işlenmeden bırakılanların da mevcut olduğunu müzelerde yer alan örneklerden bilmekteyiz. 
Mezar içinde altı gömü ve üç mezar hediyesi açığa çıkarılmıştır (Resim 2). Mezar hediyelerinden ilki silindir kesitli uç kısımları birbiri üzerine gelecek şekilde yaklaştırılmış ancak kapatılmamış bronz bir bilezik olup, herhangi bir süsleme unsuru bulunmamaktadır (Resim 3). Bu tip bileziklerin basit yapıları nedeniyle hemen hemen her dönem tercih edildiği ele geçen mezar hediyelerinden de bilinmektedir. Tarihlendirme için net bir öner vermemekle birlikte Roma Döneminde sıklıkla kullanıldığı bilinen bir malzemedir (Riha, 1990, s.54).

Mezarın kullanım dönemleri hakkında yardımcı olan bir unsur da Köşkdağı gömü alanına yakın bir noktada bulunan Gültepe Parkı Garipler Tümülüsüdür. Garipler Tümülüsünde mezar yapısı ve ritüel nesneleri tahribata uğramadan bulunmuştur, tümülüs hem mimari olarak hem de mezar buluntuları ile değerlendirilmiş ve Augustus Dönemine tarihlendirilmiştir (Yağc1, 1993, s. 122, ayrıca bknz. Uğur, 2012). İki alan arasındaki mesafenin çok kısa olması bölgenin bir nekropol alanı olduğunu destekler niteliktedir. Bu bağlamda mezarın kullanım dönemleri içinde MS 1.yy’da da kullanım görmüş olduğu önerilebilir.

Lahit mezar içinde ayrıca iki tane cam unguenterium bulunmuştur (Resim 4, 5). Bunlardan bir tanesi sağlam, diğeri parçalar halinde bulunmuştur. Söz konusu örnekler şamdan biçimli unguenteriumlar grubunda ve dış bükey küresel gövdeliler alt grubunda yer alırlar (Sönmez, 2015, s. 736; Wessberg, 1956, s. 163-164; bknz. Yağc1, 1993). Bu tip unguenteriumlar MS 1-3. yy arasına tarihlendirilmektedir (Dusenbery, 1967, s.41; Yağc1, 1993, s. 143). İkinci unguenterium parçalar halinde bulunmuş olmasına rağmen mevcut kısımlarından ilk unguenterium ile aynı özellikleri gösterdikleri anlaşılmaktadır.

Lahit tarihlendirme yapmaya olanak sağlamayacak şekilde genel özelliklere sahiptir. Buna ek olarak mezar içinde bulunan unguentariumların Hellenistik Dönem ve Roma İmparatorluk Döneminde ölü kültü ritüellerinde kullanıldıkları bilinmektedir (Akçay, 2013, s. 13-15). Burada ele aldığımız unguenterium yukarıda belirttiğimiz üzere şamdan biçimli unguenteriumların alt grubunda tanımlandığ 1 gibi aynı form ve boyutlara sahip eserlerin bazı kaynaklarda küresel gövdeli şişe (Temür ve Özbilgin 2019, s. 48-49) bazılarında ise sürahi olarak adlandırıldıkları görülmektedir (Gürler, 2000; Tekocak, 2013, s. 131-132). İsimleri farklılık göstermekle birlikte ortak özellikleri dışa çekik ağız, silindirik, gövdeye doğru daralan bir boyun ve yumuşak bir şekilde geçiş yapılan küresel gövdeye sahip olmalarıdır. Buluntu yerleri faklı olan bu eserlerin hepsi MS 3.-4. yy'a tarihlendirilmiştir. Lahit içinde bulunan cam unguenteriumlarda bu sebeplerle MS 3-4.yy içinde değerlendirilebilir. Böylece en az altı gömüye sahip, birden çok defa kullanılmış mezarın kullanım dönemlerinden birisinin MS 3-4.yy olduğunu söyleyebiliriz. En azından altı gömüye sahip olan çok defa kullanılmış mezarın kullanım dönemlerinden birisi hakkında öneri sunabilmekteyiz. 


\section{Tekne Mezarlar}

Lahit mezarın yanında üç tane bitişik şekilde yapılmış mezar bulunmuştur. Bu tip mezarlar inşa edilirken tekne kısmının plakalar ile oluşturulması nedeniyle bazı kaynaklarda plaka tekne ya da taş sandık mezar olarak adlandırılmaktadır. (Söğüt, 2012, s. 64; Hürmüzlü, 2008, s. 17-18.). Bununla birlikte tekne yapımında kullanılan plakaların bir inşa tekniği olduğu ve tekne mezar olarak adlandırılması gerektiği de bazı araştırmacılar tarafından belirtilmektedir (Terminoloji önerileri için bknz. Akçay ve Erdem 2016; Akçay, 2020). Bu tip mezarların Neolitik Dönemden itibaren kullanıldıkları bilinmektedir (Özgüç, 1948, s. 37; Kasapoğlu, 2007, s. 486) bu nedenle spesifik bir tarih vermek zordur. Batı Anadolu'da MÖ 8.yy'a kadar tarihlenebilen örnekleri bulunan (Serdaroğlu, 2005, s. 59; Söğüt, 2012, s. 64; Yalman, 1992, s. 463) plaka tekne mezarlar Helenistik Dönemde de sıklıkla kullanılmıştır (Başaran ve Kasapoğlu 2018, s. 446-447). Hem maliyet açısından uygun oluşu hem de fazla işçilik gerektirmemeleri nedeniyle uzun bir süre kullanıldıklarını söylemek yanlış olmayacaktır.

Tekne mezarların üzeri yan yana sıralanmış blok taşlarla ve devşirme olarak getirilmiş lahit kapakları ile kapatılmıştır (Resim 6).

\section{Bir Numaralı Tekne Mezar}

Ölçüleri: Uzunluk 200 cm, genişlik $80 \mathrm{~cm}$.

Mezar, kaçakçılar tarafından tahrip edilmiştir. İçinde iki adet kiremit parçasından başka hiçbir buluntuya rastlanmamıştır (Resim 8). Tegula ya da stroter olarak adlandırılan bu düz çatı kiremitleri (Çoşkun, 2007, s. 10; Bingöl, 1984, s. 52; Özyiğit, 1988, s. 103.), mezar yapımında da kullanılmaktadır (Resim 9). Bu tip kiremit mezarlar Anadolu'da Hellenistik Dönem ve Bizans Dönemi de dâhil olmak üzere yaygın biçimde kullanılmıştır (Özüdoğru, 2018, s. 119). Bir numaralı tekne mezar içinde bulunan bu kiremitler için ne amaçla kullanıldıklarını belirtmek zordur. Mezarın tahrip edilmiş olması da bu kiremitlerin orijinal yerinde olup olmadıkları konusunda soru işaretleri barındırmaktadır. Mezar içinde destek amaçlı kullanılabilecekleri gibi tekne mezarın yakınlarında yapılmış bir kiremit mezar parçaları da olabilirler. Ancak daha önce de belirttiğimiz üzere mezarın tahrip edilmesi net ifadeler kullanmamızı engellemektedir.

\section{İki Numaralı Tekne Mezar}

Ölçüleri: Uzunluk $190 \mathrm{~cm}$, genişlik $76 \mathrm{~cm}$

İki numaralaı tekne mezar, bir ve üç numaralı tekne mezarların arasında yani merkezde yer almaktadır (Resim 7). Sadece kısa kenarları için yeni bloklar kullanılmış, uzun kenarlar için her iki yanında bulunan mezarların uzun kenarları kullanılmıştır. Bu mezarın batı tarafında yer alan plaka taş, kaçakçılar tarafından kaldırılmış ancak mezar içi tahrip edilmemiştir. 
Yapılan kurtarma kazısı sonucunda mezar içinde 2 gömü olduğu belirlenmiştir. Herhangi bir mezar buluntusuna rastlanılmamıştır.

\section{Üç Numaralı Tekne Mezar}

Ölçüleri: Uzunluk $217 \mathrm{~cm}$.

Mezar in-situ olarak ele geçmiştir. Yapılan kazı çalışmaları sırasında herhangi bir gömü bulunamamıştır. Mezar içerisinde bir unguentariumun dip kısmına ait parça ele geçmiş olup (Resim 11), buluntu ortaya koyduğu form özellikleriyle Hellenistik Dönemde ortaya çıkan ve MS 1.yy'da kullanımı biten iğ gövdeli unguentariumları hatırlatmaktadır (Yıldız, 2016, s. 7; Tekocak veY1ldız 2015, s. 416; Anderson-Stojanocic, 1987, s. 107).

Köşkdağı gömü alanında açığa çıkarılan bu üç tekne mezarın, bitişik şekilde yapılmış olmaları, iki numaralı tekne mezarın içinde birden fazla gömü bulunması bu mezarların aile mezarlığı olabileceğini akla getirmektedir. Plaka tekne mezarlar içinde ölü hediyesinin bulunmayışı ve mezar tipinin kullanım süresinin spesifik bir tarih aralığında olmayışı nedeniyle ilk ve son kullanım tarihlerini belirtmek zordur. Bununla birlikte mezarlar içinde ve çalışmalar sırasında mezar yakınında bulunan seramik parçaları değerlendirildiğinde MS 1.yy içinde kullanım gördükleri söylenebilir

\section{Chamosorium Mezarlar}

Lahit mezar ve plaka tekne mezarların batısında, zemine oygu tekniği ile yapılmış iki adet chamosorium mezar açığa çıkarılmıştır (Resim 12-13). Bu mezarların etrafı kesme taştan bloklarla sınırlandırılmıştır. Ayrıca iki mezar arası kesme taş bir sıra ile bölünmüştür. Kesme taş ile yapılmış sınırlandırma duvarları tek sıradır, yapılan çalışmalarda alt kısımlarında başka bir duvar sırası belirlenememiştir. Kazı çalışmaları sırasında gömü alanında da benzer şekilde blokların bulunmayışı chamosorium mezarların etrafını sınırlayan tek sıra duvar yapısını olduğunu göstermektedir. Plaka tekne mezarlarda olduğunu düşündüğümüz gibi bu mezarlarda bir aile mezarlığı olabilir. Sahip oldukları alanı belirlemek için bu sınır duvarı yapılmış olmalıdır.

\section{Bir Numaralı Chamosorium Mezar}

Bir numaralı chamosorium mezar $85 \mathrm{~cm}$ uzunluğundadır. Mezar içinde 14 gömü belirlenmiştir. Ritüel nesnesi olarak sadece bronz bir obje bulunmuştur (Resim 14). Objenin işlevi tam olarak anlaşılamamakla birlikte bir mobilya apliği olabileceği söylenebilir (mezar içinde hiç çivi bulunmaması aplik olabileceğini düşündürmektedir). Buna ek olarak objenin dikdörtgen prizma formu ve bir kenarında zigzag şeklinde oyulmuş motif bir kalıp olabileceğini de düşündürmektedir. 


\section{İki Numaralı Chamosorium Mezar}

İki numaralı chamosorium mezar $65 \mathrm{~cm}$ uzunluğundadır. Mezar içerisinde 4 gömü belirlenmiştir. İki numaralı chamosorium mezar, hediyeleri açısından en zengin ve spesitifik tarihler veren mezardır. Mezar içerisinde bir tane cam unguenterium, bir tane altın obje ve üç tane bronz sikke bulunmuştur.

Mezar içerinde ele geçen cam unguenterium (Resim 15) MS 1.yy ve MS 3. yy arasına tarihlenen makara biçimli unguenteriumlara benzemektedir (Yağcı, 1999, s. 152). Bu tip unguenteriumlar genellikle bodur görünümlüdür, ağız ve gövde genişliklerinin birbirine yakın olması ve makaraya benzer görüntüleri sebebiyle bu ismi almışlardır (Yağcı, 1999, s. 152).

İki numaralı chamosorium mezarın içerisinden günışığına çıkarılan bir diğer eser, plaka inceliğinde altın objedir (Resim 16). Niteliği tam olarak anlaşllamayan bu parça bir yüzük kasası ya da madalyon etrafına yerleştirilen ve ana motifi çerçeveleyenbir obje olabilir.

İki numaralı chamosorium mezarın en önemli buluntuları olarak üç tane sikkeyi gösterebiliriz. İki tanesi net biçimde tarihlendirilebilmektedir (Sikkeler için ayrıca bknz. Katalog 1).

İlk sikke ön yüzünde başında çelengi ile betimlenmiş İmparator Elagabalus portresi bulunan sikkedir (Resim 17a-b). Portrenin detayları aşınmıştır. Portre her ne kadar Elagabalus'un dolgun yüz hatları ile tezatlık gösterse de var olan lejant Elagabalus'a ait olduğunu kesin olarak göstermektedir ${ }^{1}$. Arka yüzde ise Erciyes dağı bir altar üzerinde betimlenmiştir. Altarın kesim kısmında "ET B (?)" şeklinde darphane ve officina harfi yer almaktadır. Özellikle "T" harfi net olarak seçilmektedir. Arka yüz üzerinde okunabilen harflerden ve benzer örneklerden yola çıkarak "MHTPO(ПО) KAICA(PI)/ KAICARIAC “ yazdığı söylenebilir (Benzer örnekler için bknz. RPC VI no: 6649 ve BMC Capadocia no.287).

İkinci sikke üzerinde başında defne çelengi ile profilden betimlenmiş portresi bulunan Gordianus III'e aittir (Resim 18a-b). Ön yüz üzerinde “AV. KAI. M" harfleri okunabilmektedir benzer örnekler bakıldığında olasılıkla devamı "ANT. ГOPAIANOC" şeklinde olmalıdır (Sydenham, 1933, s. 131 örnek 616. B.M.C. 1899, s. 346-349, SNG von Aul. 1967: Gal. Capp., taf. 223 6531). Arka yüzde sepet içinde altı tane buğday başağı ve ET Z şeklinde darphane adı ve officina numarası yer almaktadır. Gordianus III'ün Caesarea sikkelerinde arka yüzde bu betimlemeyi diğer örneklerde de görmekteyiz.

Üçüncü sikke yüzeyi oldukça aşınmıştır (Resim 19a-b). Ön yüz üzerinde profilden betimlendiği anlaşılan imparator portresi bulunmaktadır. Ayrıca boynun hemen arkasında

1 Lejant tam okunamamakla birlikte "ANT" bölümünden yola çıkarak "AY K M AYPHAIOC ANTONEINOC” olduğu söylenebilir. 
üzerinde ne olduğu anlaşılamayan bir kontrmark bulunmaktadır. Arka yüz tanımlanamayacak biçimde aşınmıştır.

\section{Değerlendirme ve Sonuç}

Kayseri antik dönemdeki adıyla Caesarea ya da Mazaca Kappadokya bölgesi içinde yer alan önemli şehirlerden biridir. Özellikle Roma İmparatorluk döneminde önemli karargâh noktalarından birisi olduğu bilinmektedir. Günümüzde büyük bir kısmı modern şehrin altında kalmıştır. Bu durum inşaat çalışmaları sırasında antik yapı kalıntılarının kontrolsüz bir şekilde açığa çıkmasına ve kaçak kazılarla kültürel verilerin tahrip olmasına neden olmaktadır. Kayseri Müze Müdürlüğü kurtarma kazıları ile tarihi eserleri açığa çıkartmakta ve belgelemektedir. Ayrıca eserlerin literatüre kazandırılması için akademik çalışmalara da destek vermektedir.

Köşkdağı mahallesinde, kaçak kazı sonucunda tespit edilen lahit ve sonrasında yapılan kurtarma kazısı ile bir gömü alanı açığa çıkarılmıştır. Mezarların belirli bir alan ve düzen içinde yapılmış olmaları ayrıca farklı tipte mezar yapıları olması bu alanın antik şehrin nekropolünün bir parçası olabileceğini akla getirmektedir. Aynı bölgede 1971 yılında kazısı yapılan Garipler Tümülüsü de bu görüşü desteklemektedir. Ancak yukarıda belirttiğimiz üzere antik şehrin büyük bölümünün modern şehrin altında kalmış olması sistemli arkeolojik kazıları engellemektedir. Köşkdağı kurtarma kazısı gibi kazılar sonucunda buluntuların belgelenmesi ve değerlendirilmesi ile antik kentin yapısal öğeleri ve kültürel özellikleri daha iyi anlaşılabilecektir.

Gömü alanında belirlenen mezar tiplerinin hiçbiri için spesifik bir yapım tarihi önerememekteyiz. En belirgin olarak lahit mezarın Roma İmparatorluk Dönemi içinde yapıldığı söyleyebiliriz. Bunun yanında plaka tekne ve oygu mezar geleneği Anadolu'da en erken görülen mezar geleneklerinden olduğu için ayrıca kullanımlarının çok uzun süre devam etmiş olması sebebiyle ilk kullanım tarihlerini söylemek zordur.

Mezarlar içinden gelen ölü hediyeleri değerlendirildiğinde MS 1.yy'dan MS. 3yy ortalarına kadar tarihlendirme yapılabilmektedir. Ayrıca mezarların çoğunun içinde birden fazla gömü olması, mezarların belirli aralıklarla kullanıldı̆̆ı göstermekte ve ölü hediyeleri arasındaki zamansal farkları açıklamaktadır.

Köşkdağ1 gömü alanında plaka tekne ve oygu mezarların kendi içlerinde bir düzende yerleştirilmeleri ve birden fazla gömüye sahip olmaları aile mezarlığı olarak kullanılmış olabileceklerini göstermektedir. Lahit mezar tekil olarak bulunsa da plaka tekne mezarlara olan yakınlığı ve birden fazla gömüye sahip olması bu mezarın da aile üyeleri için tekrar açılarak kullanıldığını düşündürmektedir. Olasılıkla farklı maddi imkânlara sahip aileler tarafından nekropol içinde alınmış mezarlık adacıklarıydılar. 
Kurtarma kazısı sonucunda açığa çıkarılan mezarlar antik dönemde Kayseri'de ölü gömme geleneğinin çeşitliliğini, ayrıca oygu mezarlar içinde ele geçen sikkeler MS 3.yy ortalarına kadar bu alanın gömü için kullanıldığını göstermektedir. Mezarlar ve buluntuları ilerleyen zamanda açığa çıkarılan mezar tipleri ve kullanım dönemleri için bir kaynak olarak kullanılabilecek niteliktedir.

Teşekkür: Bu alanda açığa çıkarılan mezarların ve buluntularının çalışılmasında gerekli izinleri veren, çalışmamda her türlü doküman yardımında bulunan Kayseri Müze Müdürlüğüne ve çalışanlarına ayrıca teşekkür ederim.

Hakem Değerlendirmesi: Dış bağımsız.

Çıkar Çatışması: Yazar çıkar çatışması bildirmemiştir.

Finansal Destek: Yazar bu çalışma için finansal destek almadığını beyan etmiştir.

Peer-review: Externally peer-reviewed.

Conflict of Interest: The author has no conflict of interest to declare.

Grant Support: The author declared that this study has received no financial support.

\section{Kaynakça/References}

Akçay, T. (2013). Olba'da Şeytanderesi Vadisi’ndeki Kaya Kült Alanında Bulunan Unguentariae. Seleucia ad Calycadnum, 3, 9-29.

Akçay, T. ve Erdem, B. (2016). Doğu Dağlık Cilicia Mezarları, Olba'dan Yeni Mezar Tipleri ve Terminoloji Önerileri. Seleucia ad Calycadnum, 6, 261-286.

Akçay, T. (2020). Terminoloji Sözlüğü Antik Çă̆’da Ölüm. Ankara: Bilgin Kültür Sanat Yayınları.

Anderson- Stojanovic, V. R. (1987). The Chronology and Function of Ceramic Unguentaria. AJA 91, 105122.

Başaran, C.ve Kasapoğlu, H. (2018). 2005-2013 Yılları Verileriyle Parion Güney Nekropolisi Ölü Gömme Gelenekleri. XVII. Türk Tarih Kongresi I. Cilt Eski Anadolu Uygarliklarl, Ankara: Türk Tarih Kurumu Yayınları, 432-487.

Bingöl, O. (1984). Bayraklı Çatı Kiremitleri. Anadolu/Anatolia 20, 51-81.

B.M.C. (1899). Wroth, W., Catalogue of Greek Coins in the British Museum, Galatia, Cappadocia and Syria. Çoşkun, A. (2007). Salamis Kenti Çatı Kiremitleri Üzerine Bazı Gözlemler. Anadolu/Anatolia 33, 207: 9-24.

Dusenbery, E. (1967). Ancient Glass From The Cemeteries Of Samothrace. Journal of Glass Studies, 9, 3449. from www.jstor.org/stable/24182745

Gürler, B. (2000). Tire Müzesi Cam Eserleri. Ankara: T.C. Kültür Bakanlığı Milli Kütüphane Basımevi.

Hürmüzlü, B. (2008). Eski Yunan'da Ölü Gömme Gelenekleri. İstanbul: Türk Eskiçağ Bilimleri Entistüsü Yayınları.

Kasapoğlu, H. (2007). Parion Nekropolü Mezar Tipleri. Doğudan Yükselen Işık: Arkeoloji Yazıları, Erzurum, 481-521.

Koch, G. (2010). Türkiye'deki Roma Imparatorluk Dönemi Lahitleri= Sarkophage Der Römischen Kaiserzeit in Der Türkei. Antalya: Akmed.

Özgüç, T. (1948). Ön Tarih'te Anadolu'da Ölü Gömme Adetleri. Ankara: Türk Tarih Kurumu Yayınları.

Özüdoğru, Ş. (2018). Kibyra 2014-2016 Yılı Çalışmaları ve Sonuçları. Phaselis IV, 109-146. 
Özyiğit, Ö (1988). Antik Çatılarda Dere Kiremitleri. Sanat Tarihi Dergisi 4 (4), Ocak.

Riha, E. (1990). Der romische Schmuck aus Augst und Kaiseraugst. Augst: Amt fur Museen und Archaologie des Kantons Basel-Landschaft.

Serdaroğlu, Ü. (2005). Behramkale-Assos. İstanbul: Arkeoloji ve Sanat Yayınları.

SNGvon Aul. (1967). : Sylloge NummorumGraecorum. Deutschland.Sammlung v.Aulock. GalatienKappadokien-Kaiserzeitliche Kistophoren-Posthume Lysimachus und Alexander - Tetradrachmen Incerti, 14.Heft, Berlin.

Söğüt, B. (2012). Börükçü 2003-2006 Yılları Kazıları. B. Söğüt (Ed.), Stratonikeia'dan Lagina'ya, A. A. Tirpan'a Armağan, İstanbul, 553-586.

Sönmez, B., E. (2015). Nevşehir Müzesi’nde Bulunan Cam Unguentariumlar. Uluslararası Sosyal Araştırmalar Dergisi, 8 (41), Aralık, 733-746.

Sydenham, E., A. (1933). The Coinage of Caesarea in Cappadocia, London.

Şirin, O., A.-Kolağasığlu ,M. (2017). Amisos Nekropolü Basit Toprak Mezar ve Kiremit Mezar Geleneği. Uluslararasl Amisos Dergisi, 2( 2), 1-29.

Tekocak, M. (2013). Akşehir Nasreddin Hoca Arkeoloji Müzesinden Bir Grup Cam Eser. Anadolu Antik Cam Araştırmaları Sempozymu, Kaunos/Kbid toplantıları2, Bilgin Kültür ve Sanat Yayınları, 127-142.

Tekocak, M. ve Yıldız, V. (2015). Akşehir Nasreddin Hoca Arkeoloji ve Etnoğrafya Müzesi’nde Bulunan Bir Grup Pişmiş Toprak Vazo. Prof. Dr. Ömer Özyiğit'e Armă̆an (Studies in Honour of Ömer Özyiğit), Cenker Atila - Emre Okan (Eds.), İstanbul: Ege Yayınları, s.413- 432.

Temür, A. ve Özbilgin, Ö (2019). Samsun Müzesi Koleksiyonundan Bir Grup Cam Şişe, TÜBA-KED 202019, 41-72.

Uğur, H. (2012). Garipler Tümülüsü. (Yüksek Lisans Tezi). Selçuk Üniversitesi Sosyal Bilimler Enstitüsü, Arkeoloji Anabilim Dalı, Klasik Arkeoloji Bilim Dalı, Konya.

Yalman, B. (1992). Antandros Nekropol Kazıs1. III. Müze Kurtarma Kazıları Semineri, 449-487.

Yağcı, E., E. (1993). Başlangıcından Geç Antik Dönem Sonuna Kadar Anadolu'da Cam. (Doktora Tezi). Ankara Üniversitesi Sosyal Bilimler Enstitüsü, Ankara.

Y1ldız, V. (2016). Akhisar Arkeoloji Müzesi’nde Bulunan Unguentariumlar. Cbü Sosyal Bilimler Dergisi, 14(1), Mart.

Wessberg, O. (1956). Glass: Typology- Chronology. Swedish Cyprus Expedition, IV, 3, 128-174.

\section{İnternet Kaynakları}

RPC https://rpc.ashmus.ox.ac.uk/search/browse?volume_id=11

https://rpc.ashmus.ox.ac.uk/coins/6/6649 


\section{KATALOG}

\section{ELAGABALUS (MS 218-222)}

Ö/ [AY K M AYPHᄉIOC] ANT[ONEINOC]. Elagabalus’un defne çelenkli büstü sağa. A/ ET B / [MHTPO(ПО) KAICA(PI)/ KAICAIAC]. Erciyes dağı bir altar üzerinde Ref: RPC VI no: 6649 ve BMC Capadocia no.287.

AE 6,4 gr 22mm 6 Müze Envanter no:2018/63

\section{GORDİANUS III (MS 238-244)}

Ö./ AV. KAI. M [ANT. ГOP $\triangle$ IANOC]. Gordianus III'ün defne çelenkli büstü sağa.

A/ ET Z. Sepet içinde altı tane buğday başağı betimlenmiştir.

Ref.: Sydenham, 1933, s. 131 örnek 616. B.M.C. 1899, s. 346-349, SNG von Aul. 1967: Gal. Capp., taf. 223 6531

AE 13,gr 28mm 6 Müze Envanter no (Etütlük) 6750

\section{ELAGABALUS (?) (MS 218-222) /GORDİANUS III(?) (MS 238-244)}

Ö./ İmparator Portresi sağa.

A./ Düşük kondüsyon

AE 9,6gr 26 mm 12 Müze Envanter no (Etütlük) 6751 


\section{RESIMMLER}

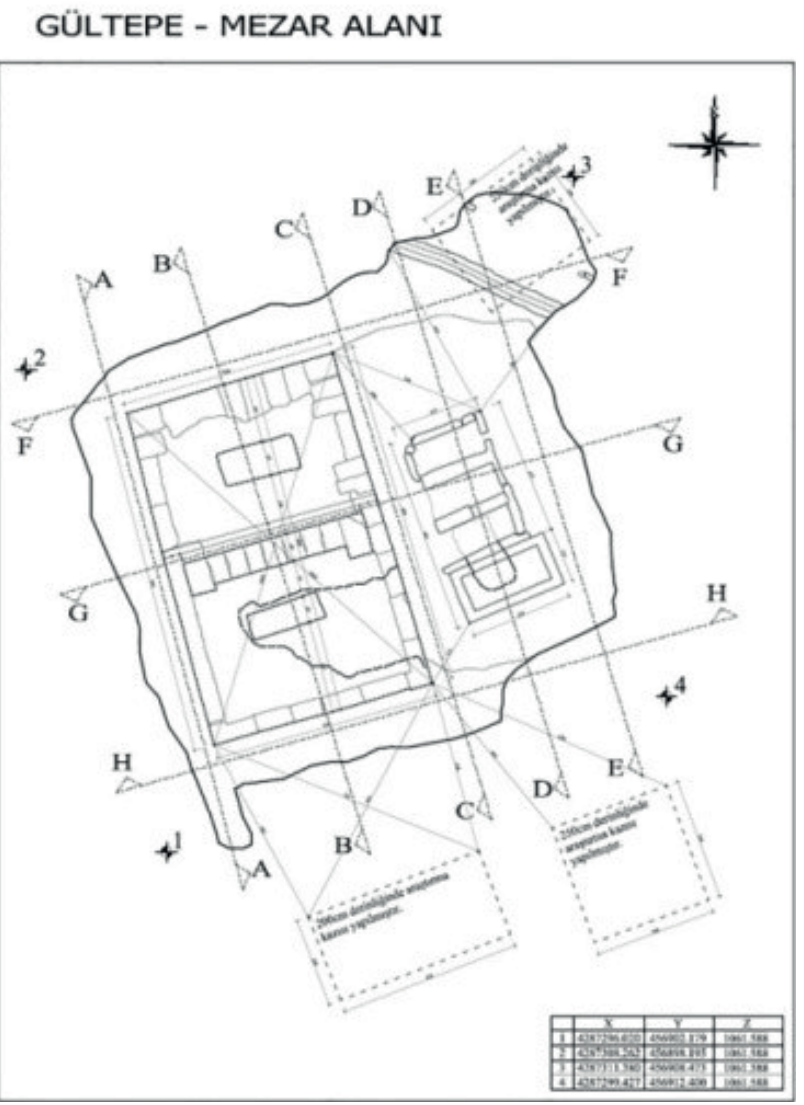

Çizim 1. Gültepe Mezar Alanı. 


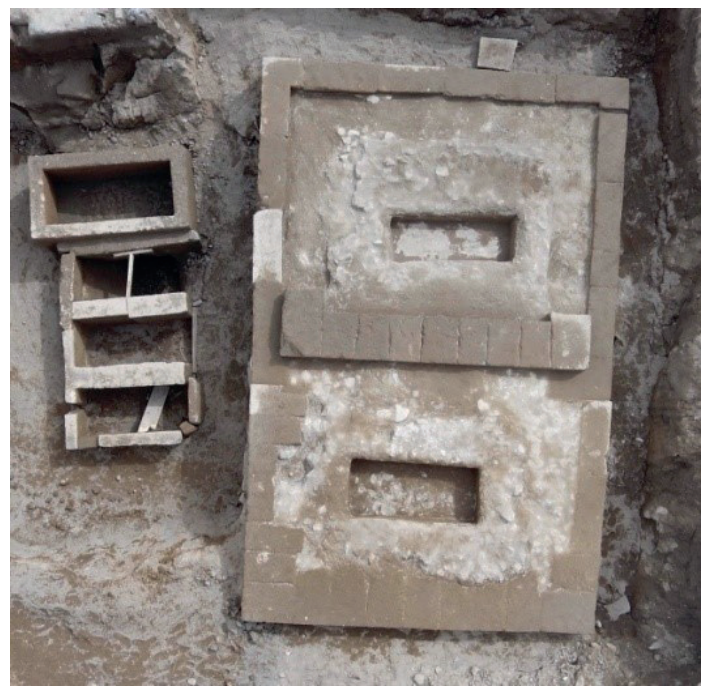

Resim 1. Gültepe Mezar Alanı.

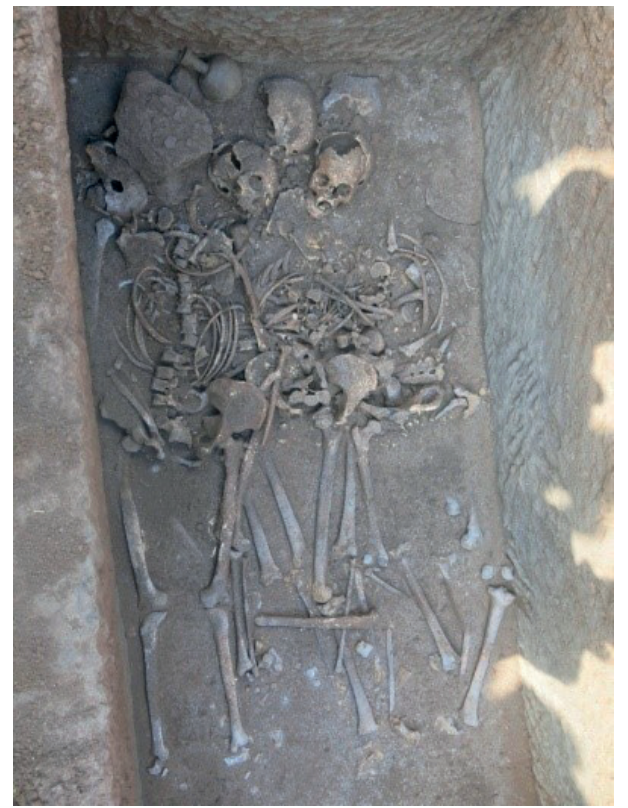

Resim 2. Bir Numaralı Lahit, gömüler. 


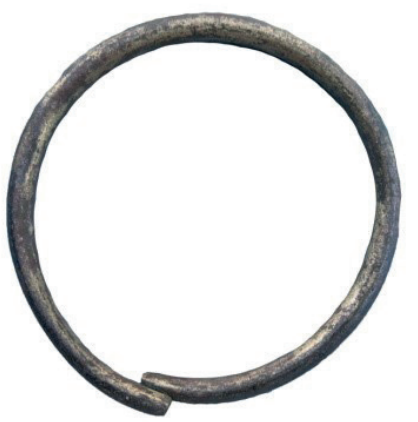

Resim 3. Bir Numaralı Lahit içinden bulunan bronz bilezik.

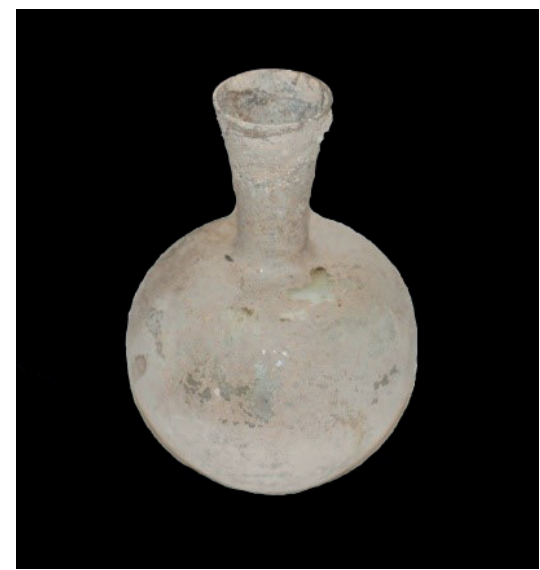

Resim 4. Bir Numaralı Lahit içinden bulunan cam unguenterium.

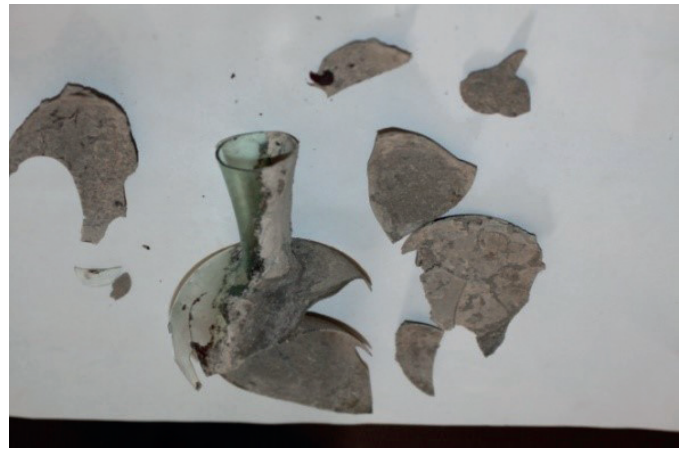

Resim 5. Bir Numaralı Lahit içinden bulunan cam unguenterium parçaları. 


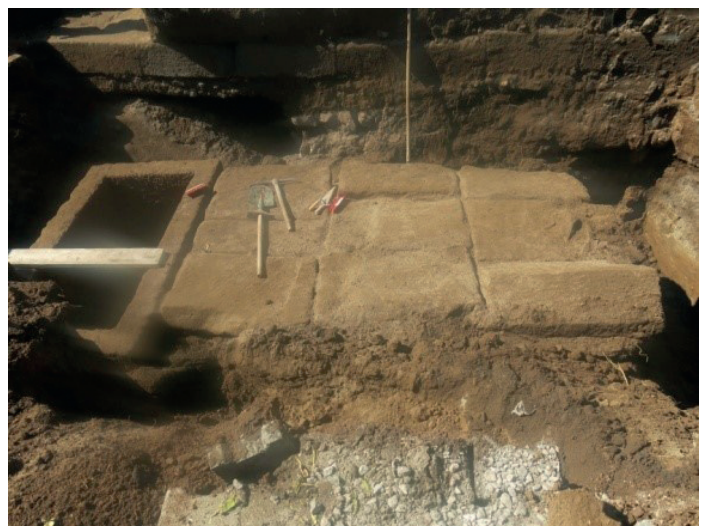

Resim 6. Plaka Tekne Mezarlar.

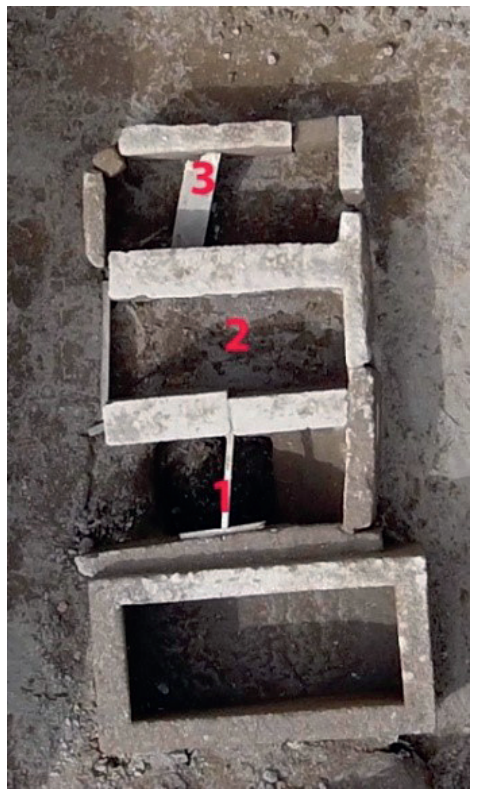

Resim 7. Gültepe Mezar Alanı numaralandırılmış Plaka Tekne mezarlar. 


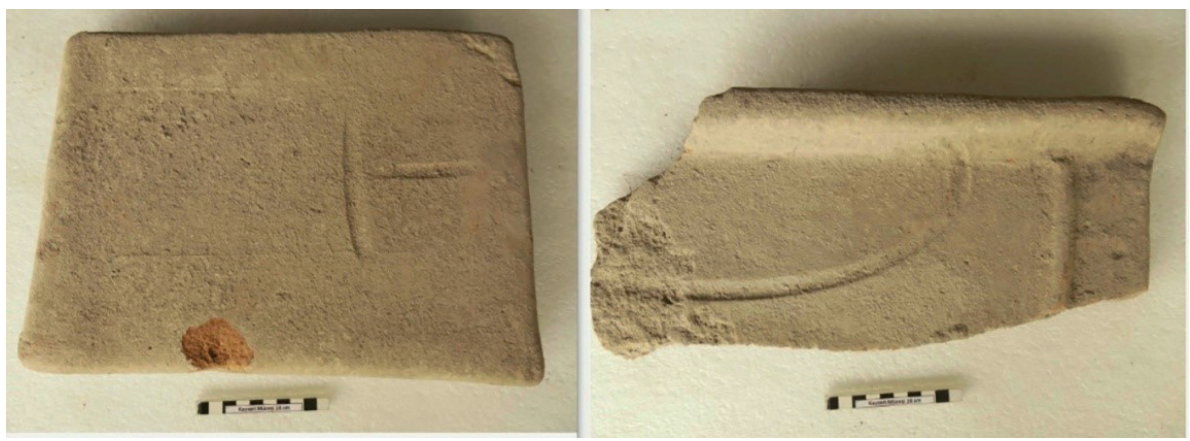

Resim 8. Bir Numaralı Plaka Tekne Mezar içinden bulunan kiremitler.

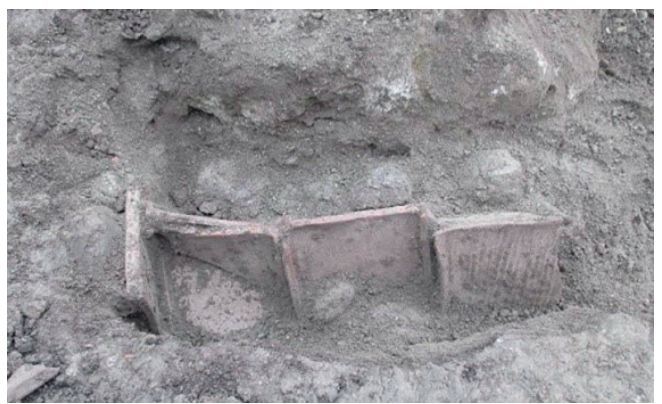

Resim 9. Amisos'tan Kiremit Mezar örneği. Şirin-Kolağasığlu 2017, Resim 21a.

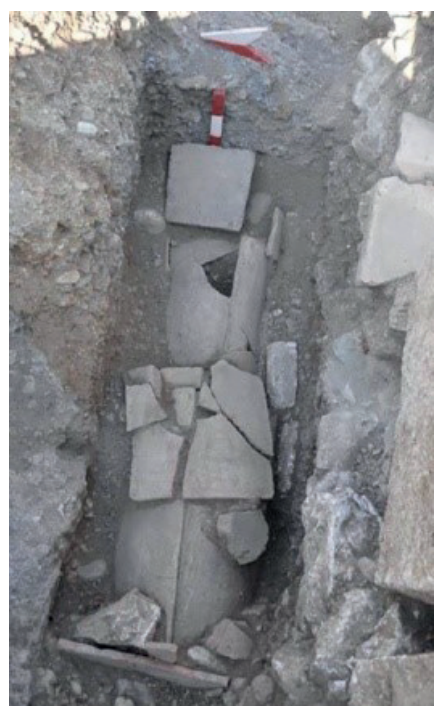

Resim 10. Kibyra'dan Kiremit Mezar örneği. Özüdoğru 2018, fig.17. 

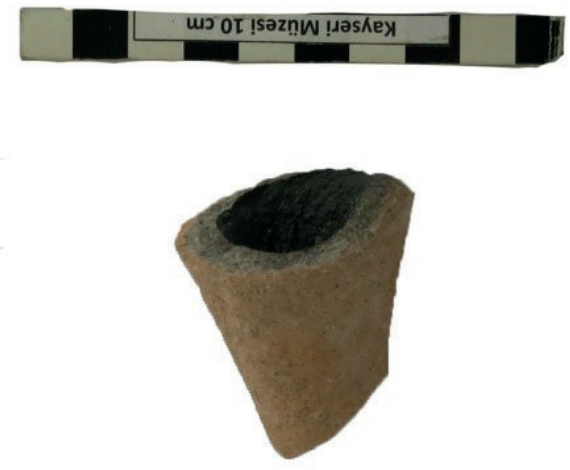

Resim 11. Üç Numaralı Plaka Tekne Mezardan bulunmuş unguenterium parçası.

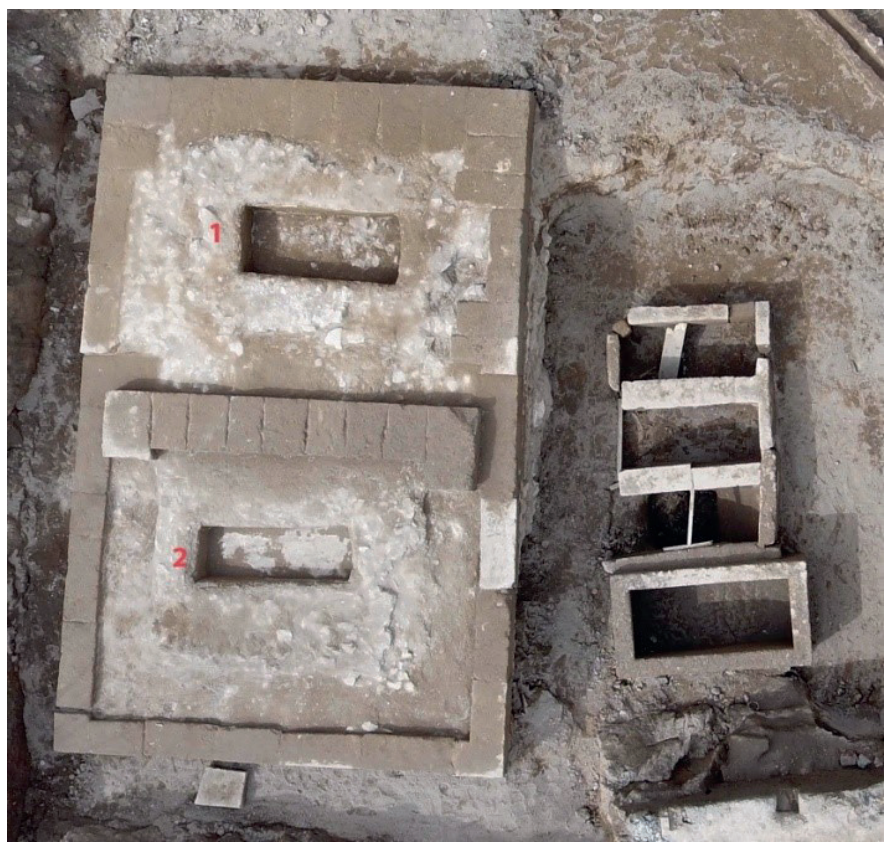

Resim 12. Oygu Mezarlar. 


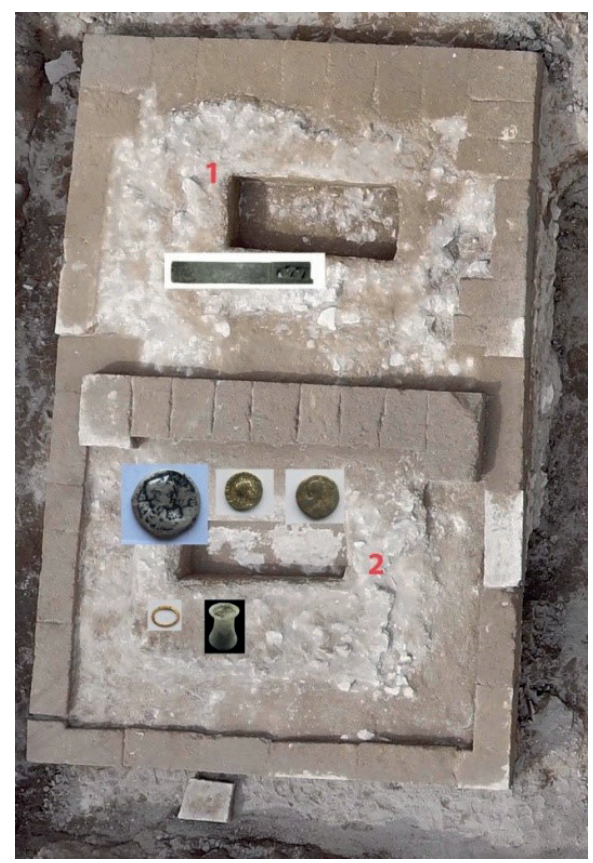

Resim 13. Oygu Mezarlar ve buluntuları.
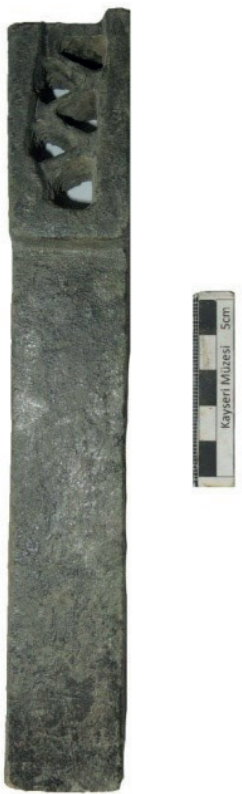

Resim 14. Bir numaralı oygu mezar içinden bulunan bronz obje (kalıp?). 


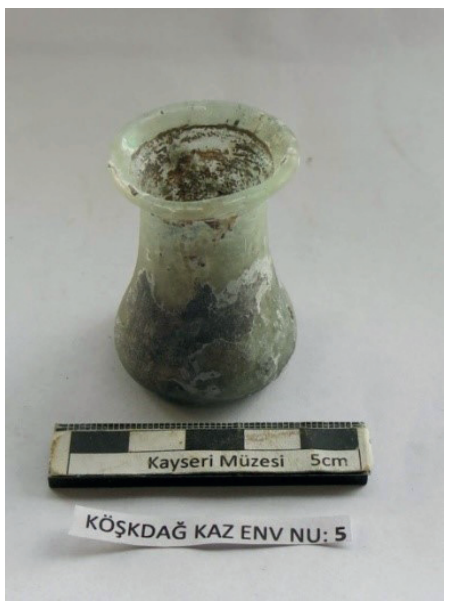

Resim 15. İki numaralı oygu mezar içinden bulunan cam unguenterium.

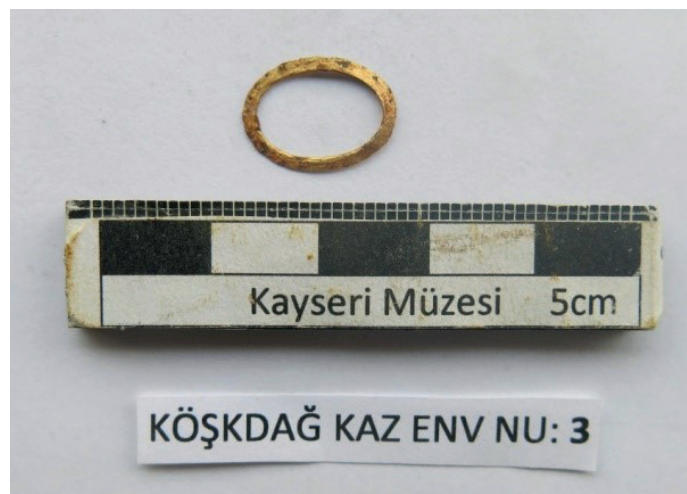

Resim 16. İki numaralı oygu mezar içinden bulunan altın obje.

a

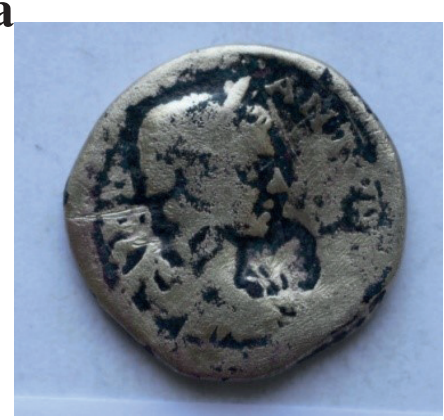

b

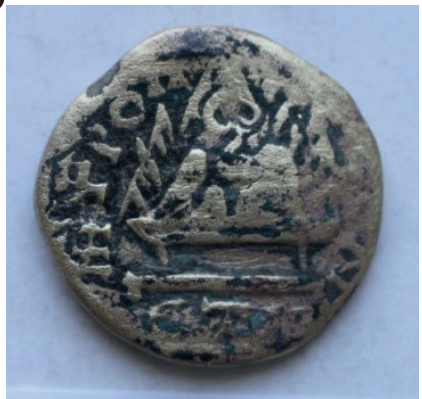

Resim 17. a) İki numaralı oygu mezar içinden bulunan Elagabalus sikkesi ön yüz,

b) İki 2 numaralı oygu mezar içinden bulunan Elagabalus sikkesi arka yüz. 
a

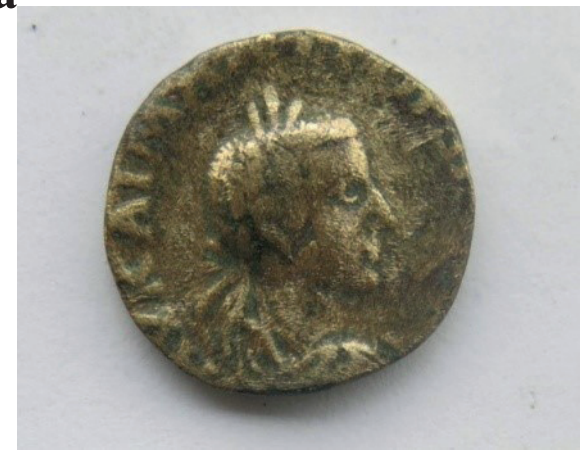

b

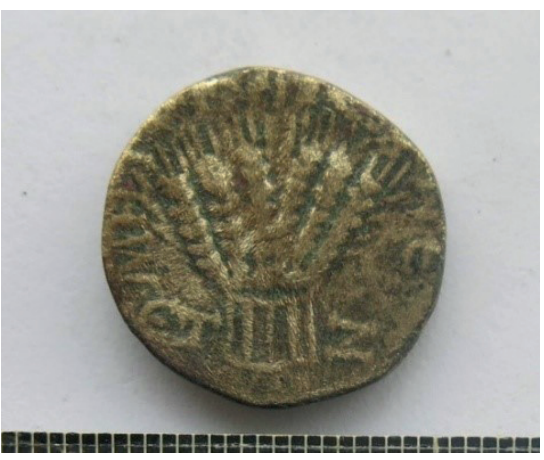

Resim 18. a) İki numaralı oygu mezar içinden bulunan Gordian III sikkesi ön yüz, b) İki numaralı oygu mezar içinden bulunan Gordian III sikkesi arka yüz.

a

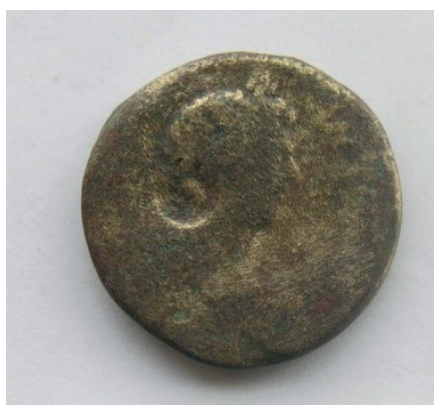

b

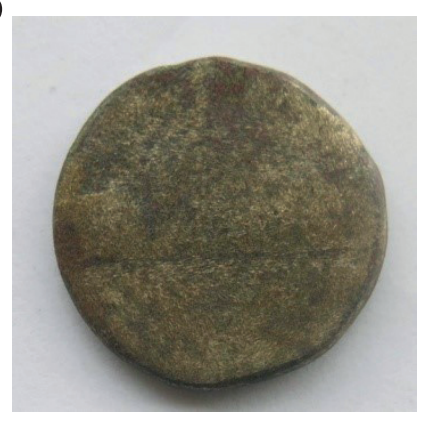

Resim 19. a) İki numaralı oygu mezar içinden bulunan sikke ön yüz, b) İki numaralı oygu mezar içinden bulunan sikke arka yüz. 